\title{
CARDIO-RESPIRATORY FITNESS OF YOUNG AND OLDER ACTIVE AND SEDENTARY MEN
}

\author{
L. A. STEINHAUS*, R. E. DUSTMAN* $*$, R. O. RUHLING§, R. Y. EMMERSON* \\ J. W. SHIGEOKATt and W. H. BONEKAT‡¥ \\ *Neuropsychology Research (151A), Veterans Administration Medical Center, Salt Lake City, UT \\ tDepartment of Neurology, School of Medicine, University of Utah, Salt Lake City, UT \\ ¥Department of Psychology, University of Utah, Salt Lake City, UTA \\ §Chairman, Department of Health, Sport and Leisure Studies, George Mason University, Fairfax, VA \\ " Department of Physical Education, College of Health, University of Utah, Salt Lake City, UT \\ t+Pulmonary Department, Veterans Administration Medical Center, Salt Lake City, UT \\ $¥ ¥$ Pulmonary Department, Veterans Administration Outpatient Clinic, Sacramento, CA
}

\section{ABSTRACT}

Physiological profiles are described for 30 healthy young (20-31 years) and 30 healthy older (50-62 years) men. Half of the individuals in each group reported that during the previous five years they participated frequently in strenuous physical exercises; the other half reported sedentary lifestyles. A treadmill exercise test was used to determine maximal aerobic power $\left(\mathrm{VO}_{2} \mathrm{max}\right)$. Heart rate and blood pressure were measured during rest, maximal exercise and recovery. The active older men demonstrated significantly lower resting heart rates, lower resting systolic and diastolic blood pressures, higher $\mathrm{VO}_{2} \mathrm{max}_{\text {, }}$ lower maximal exercise diastolic blood pressure and lower recovery heart rates than the age-matched sedentary men. Compared with the young sedentary men, the older active men had lower resting heart rates and higher $\mathrm{VO}_{2}$ max, walked longer on the treadmill, had lower recovery heart rates and weighed less. Older active men also had higher $\mathrm{VO}_{2}$ max levels than young sedentary men. In summary, physiological profiles of the older active men more closely resembled profiles of active men who were $\mathbf{3 0}$ years younger than those of older sedentary men. These results emphasise the range of benefits associated with exercise.

Key words: Maximal aerobic power, $\mathrm{VO}_{2} \max$, Ageing, Fitness

\section{INTRODUCTION}

Being physically fit has been associated with "the ability to carry out daily tasks without undue fatigue and with ample energy to enjoy leisure-time pursuits and to meet unforeseen emergencies" (United States President's Council of Physical Fitness, 1977). Such fitness is reflected in specific measures of work capacity and oxygen uptake (Cooper, 1977) and more globally in increased vigour (deVries, 1975), decreased incidence of chronic diseases (Blackburn, 1983; Paffenbarger et al, 1986), enhanced relaxation (deVries et al, 1981), improved performance on neuropsychological tests of mental flexibility and faster response time (Dustman et al, 1984). It has also been suggested that a physically active lifestyle may reduce by half the age-related decline in maximal aerobic power and other measures of physical fitness (Dehn and Bruce, 1972; Heath et al, 1981).

It has been well documented that consistent participation in aerobic exercises is accompanied by improvement in maximal oxygen uptake $\left(\mathrm{VO}_{2} \mathrm{max}\right)$, a measure of oxygen utilisation efficiency (Larsen and Bruce, 1987), but the physiological characteristics and magnitude of differences between individuals who lead sedentary and physically active lifestyles have not been described adequately. We have conducted maximal exercise stress tests on young and old physically active and inactive men in order to describe maximal aerobic power and cardiovascular reactivity for these individuals at rest, during maximal exercise and during recovery from exercise. The major objective of the study was to extend what is presently known about the effects of a lifestyle of continuous aerobic exercise participation. To this end we studied older groups of physically active (high fit) and sedentary (low fit) men and compared

Address for correspondence:

R. E. Dustman, PhD (151A)

Director, Neuropsychology Laboratory

Veterans Administration Medical Center

500 Foothill Drive

Salt Lake City, Utah 84148

USA their physiological profiles with those of much younger high and low fit men.

\section{METHODS}

Subjects

Four groups, each of 15 healthy, non-smoking male volunteers, were selected on the basis of exercise history and documented fitness level $\left(\mathrm{VO}_{2}\right.$ max): young high fit $(\bar{x}=24, s d=2.9$ years $)$, young low fit $(\bar{x}=26$, sd $=2.6$ years), older high fit ( $\bar{x}=54$, sd $=3.0$ years), and older low fit $(\bar{x}=56, s d=3.2$ years). Fitness levels were documented by a maximal exercise test on a motor driven treadmill during which a standard open-circuit indirect calorimetry system was used so that measures of minute ventilation and $\mathrm{VO}_{2} \max \left(\mathrm{ml} \mathrm{kg}^{-1} \mathrm{~min}^{-1}\right)$ could be obtained. Only those whose age-adjusted $\mathrm{VO}_{2} \max (C o o p e r, 1977)$ indicated their fitness level was either "excellent" to "superior" (high fit men) or "fair to poor" (low fit men) were included in the study. Maximal oxygen uptake of an additional 19 prospective subjects did not meet these fitness criteria; they were not studied further. The weekly frequency, estimated energy expenditure and type of aerobic activity engaged in by the young and old high fit subjects are outlined in Table $\mathrm{I}$.

TABLE I

Average weekly frequency, estimated energy expenditure, and type of exercise of 15 young and 15 old high fit men

Exercise Type

MJ

Triath = Combination of jogging, bicycling, swimming

$\mathrm{BB}=$ Full court basketball

Wrest $=$ Wrestling (competitive)

Aerobics $=$ Aerobics dance instructor 
Energy expenditure was estimated from self-reports of exercise frequency, intensity and duration and from energy expenditure equations found in Fox and Matthews (1981, p. 534). Medical history and physical activity questionnaires were completed by all subjects. Subjects were paid for participation in the study.

\section{Maximal Exercise Test}

The Human Performance Research Laboratory at the University of Utah was the setting for the maximal exercise test. Subjects were required to report to the laboratory at least 2 hours post-prandial. Body weight and height were recorded and each subject was seated quietly on the treadmill for a minimum of 5 minutes whilst resting heart rate and blood pressure were recorded. Heart rate and rhythm were monitored continuously with an electrocardiograph (CM5 lead configuration) throughout the rest, exercise and recovery periods. Determination of blood pressure was performed by the indirect brachial artery auscultation technique. The first and third Korotkoff sounds were recorded with a mercury sphygmomanometer and a stethoscope. Blood pressure was recorded during the third and fifth minutes of rest, and every third minute during exercise until the subject neared $\mathrm{VO}_{2}$ max when it was taken every minute. Blood pressure was taken every 3 minutes during the recovery period.

The maximal exercise test was performed on a Haden Pacer R-9 motor driven treadmill using a Modified Balke Multistage Progressive Treadmill Protocol $\left(1.48 \mathrm{~m} . \mathrm{s}^{-1}\right.$ [3.3 $\mathrm{mph}$ ] speed and $1 \%$ increase in slope per minute) (Balke and Ware, 1959) for all but the young high fit subjects who were tested at a speed of $1.67 \mathrm{~m} . \mathrm{s}^{-1}(3.7 \mathrm{mph})$. Data on heart rate, ventilation, and oxygen uptake were read from a visual display on a computer print-out each minute. Criteria for $\mathrm{VO}_{2}$ max included: attainment of the subject's agepredicted maximal heart rate, a rise of oxygen consumption

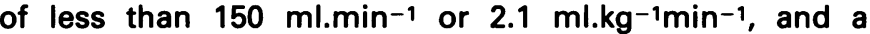
respiratory exchange ratio greater than or equal to 1.0
(Taylor et al, 1955). The maximal exercise test was to be terminated if subjects demonstrated greater than 6 premature ventricular depolarisations (PVDs) per minute, if systolic blood pressure fell $20 \mathrm{mmHg}$ in one minute despite increasing work rate, or if subjects indicated they could not continue another minute (American College of Sports Medicine, 1986). No tests were terminated before the subject achieved $\mathrm{VO}_{2}$ max criteria. A physician was present during all exercise tests of older low fit men.

Subjects in the four groups were compared with respect to heart rate, systolic and diastolic blood pressure at rest, maximal heart rate, $\mathrm{VO}_{2}$ max, maximal systolic and diastolic blood pressure, time on the treadmill, and heart rate during the fifth minute of recovery from exercise.

\section{RESULTS}

The physiological indicators of maximal aerobic power during the maximal exercise test and the results of Age $\times$ Fitness ANOVAs are described in Table II. A summary of the relationships between age and fitness is found in Table III. Significant age $\times$ fitness interactions occurred with resting systolic blood pressure (SBP) and with diastolic blood pressure (DBP) during maximal effort (see Fig. 1).

The older aerobically high fit men were compared with the young low fit men on cardiorespiratory measures known to change during adult ageing (t-tests for independent groups). Compared with young low fit men, older high fit subjects had lower weight $(P<0.05)$, lower resting heart rate $(P<0.001)$, longer treadmill time $(P<0.001)$, higher $\mathrm{VO}_{2} \max (P<0.001)$, and lower recovery heart rate $(\mathrm{P}<0.001) . \mathrm{VO}_{2}$ max values for the young and old high and low fit subjects are depicted in Fig. 2.

\section{DISCUSSION}

$\mathrm{VO}_{2}$ max normally declines with ageing, at a rate of about $\mathbf{9 \%}$ per decade for physically inactive people. The rate of decline is substantially slowed (to about $5 \%$ ) in those who

TABLE II

Means, standard deviations and p-values resulting from Age $\times$ Fitness ANOVAs computed on physiological measurements obtained from young and old men with high and low fitness levels during rest (mean of 5 minutes sitting), maximal exercise and after five minutes recovery from maximal exercise stress testing conditions. See Table III for group mean comparisons

\begin{tabular}{|c|c|c|c|c|c|c|c|c|c|c|c|}
\hline & \multicolumn{4}{|c|}{ Young } & \multicolumn{4}{|c|}{ Old } & & & \\
\hline & \multicolumn{2}{|c|}{ High Fit } & \multicolumn{2}{|c|}{ Low Fit } & \multicolumn{2}{|c|}{ High Fit } & \multicolumn{2}{|c|}{ Low Fit } & \multicolumn{3}{|c|}{ Significance Level } \\
\hline & Mean & SD & Mean & SD & Mean & SD & Mean & SD & Age & Fitness & $A \times F^{*}$ \\
\hline \multicolumn{12}{|l|}{ Rest } \\
\hline HR & 72 & 7 & 85 & 13 & 64 & 10 & 81 & 10 & $<0.04$ & $<0.001$ & ns \\
\hline SBP & 131 & 14 & 127 & 11 & 130 & 8 & 142 & 15 & $<0.04$ & ns & $<0.02$ \\
\hline DBP & 83 & 9 & 86 & 8 & 87 & 8 & 95 & 6 & $<0.005$ & $<0.01$ & ns \\
\hline \multicolumn{12}{|l|}{ Exercise } \\
\hline HR & 190 & 9 & 192 & 9 & 164 & 14 & 165 & 11 & $<0.001$ & ns & ns \\
\hline $\mathrm{VO}_{2} \max$ & 60 & 6 & 38 & 6 & 50 & 6 & 29 & 4 & $<0.001$ & $<0.001$ & ns \\
\hline SBP & 206 & 24 & 188 & 21 & 188 & 25 & 186 & 29 & ns & ns & \\
\hline DBP & 79 & 8 & 80 & 9 & 79 & 11 & 91 & 8 & $<0.025$ & $<0.01$ & $<0.025$ \\
\hline \multicolumn{12}{|l|}{ Recovery } \\
\hline HR & 109 & 12 & 117 & 11 & 92 & 17 & 108 & 10 & $<0.001$ & $<0.001$ & ns \\
\hline
\end{tabular}

*Age $\times$ Fitness interaction

ns $=$ not significant

$\mathrm{HR}=$ Heart rate (beat $\min ^{-1}$

SBP = Systolic blood pressure $(\mathrm{mmHg})$

DBP = Diastolic blood pressure $(\mathrm{mmHg})$

$\mathrm{VO}_{2}$ max expressed in $\mathrm{ml}^{.} \mathrm{kg}^{-1} \mathrm{~min}^{-1}$ 
TABLE III

Age and Fitness comparisons for rest (mean of 5 minutes sitting), maximal exercise and recovery from maximal exercise conditions. See Table II for group means and p-values

\begin{tabular}{lcc}
\hline & Age & Fitness \\
\hline Rest & Old < Young & High < Low \\
HR & Old > Young & Old High < Old Low \\
SBP & Old > Young & High < Low \\
DBP & Old < Young & ns \\
Exercise & Old < Young & High $>$ Low \\
HR & ns \\
VO, max & Old > Young & Old High < Old Low \\
SBP & & High < Low \\
DBP & Old < Young & \\
Recovery & & \\
HR & &
\end{tabular}

ns = not significant

$H R=$ Heart rate (beat $\min ^{-1}$ )

SBP = Systolic blood pressure $(\mathrm{mmHg})$

DBP = Diastolic blood pressure $(\mathrm{mmHg})$

$\mathrm{VO}_{2}$ max expressed in $\mathrm{ml}^{.} \mathrm{kg}^{-1} \mathrm{~min}^{-1}$
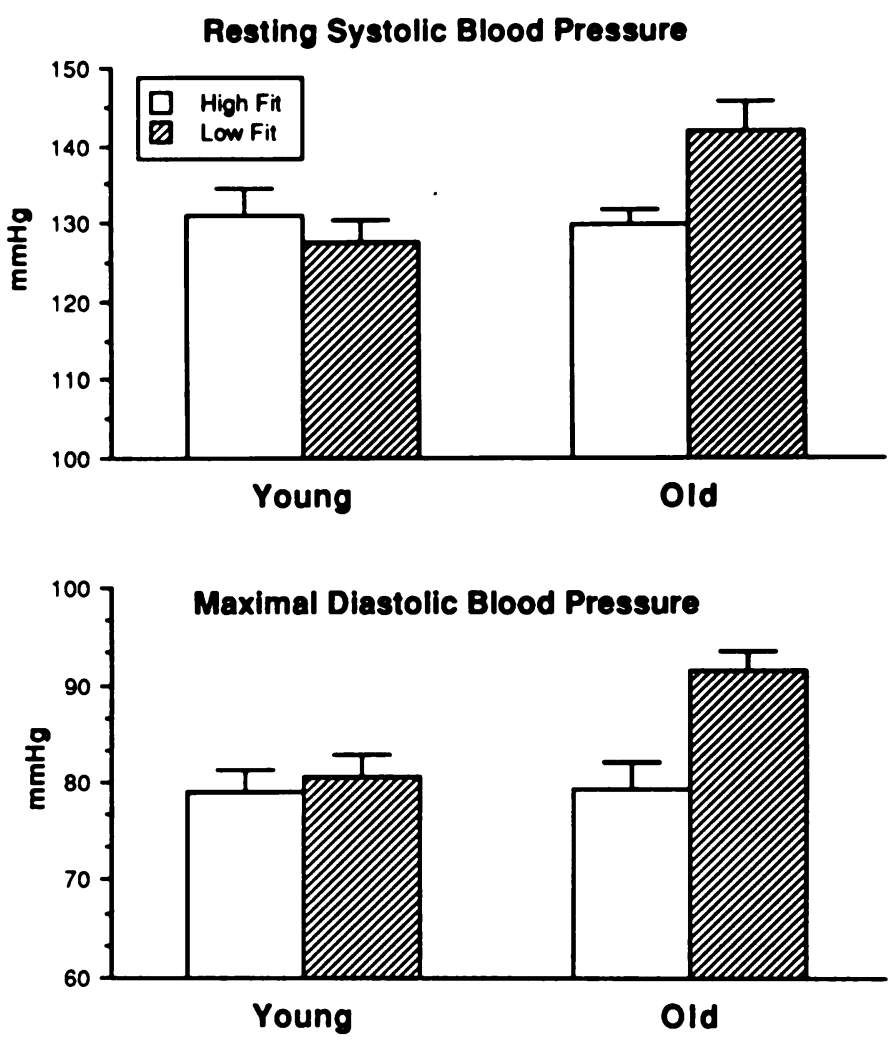

Fig. 1: Comparisons of young and old men with high and low fitness levels on systolic blood pressure at rest and diastolic blood pressure during maximal effort. Vertical bars show standard errors of the mean.

practise a physically active lifestyle (Heath et al, 1981). Our results, illustrated in Fig. 2, demonstrated that $\mathrm{VO}_{2}$ max of 55-year-old active men was not only much higher than that of their sedentary counterparts, but was significantly higher than $\mathrm{VO}_{2}$ max of sedentary men who were 30 years younger. Compared with the older sedentary men, the high fit older subjects had significantly lower resting heart rates and blood pressures and lower recovery heart rates, in addition to higher $\mathrm{VO}_{2}$ max and longer time on the treadmill. Thus, the physiological benefits of regular exercise for the older high fit subjects extended beyond

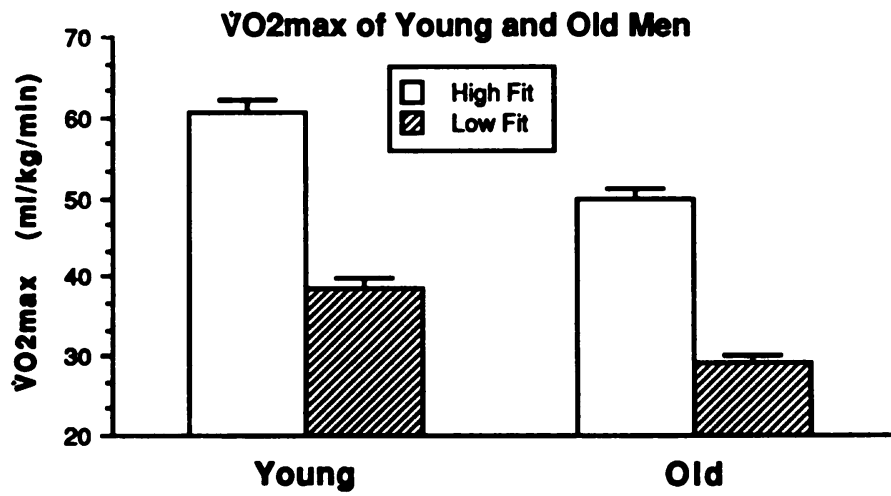

Fig. 2: $\mathrm{VO}_{2}$ max of young and old men with high and low fitness levels. Vertical bars show standard errors of the mean.

performance on the treadmill to improved cardiovascular performance during resting annd recovery conditions. It is notable that a relationship between physical activity (up to 14.7 MJ (3,500 Kcal) per week) and lower coronary heart disease (CHD) risk has been demonstrated (Paffenbarger et al, 1986). Our active older subjects expended an estimated 14.2 MJ $(3,400 \mathrm{Kcal})$ of energy per week in aerobic activities, and all subjects who reported vigorous aerobic exercise participation had $\mathrm{VO}_{2}$ max levels in the "excellent" or "superior" category (Cooper, 1977). Exercise which increases maximum aerobic power may be directly related to reduced CHD risk through improved cardiovascular responses such as those evidenced by our active subjects.

It might be argued that the high maximal aerobic power and exercise stamina of older active men reflects a biologic predisposition toward high physical fitness. Endurance and $\mathrm{VO}_{2}$ max are, in part, heritable traits (Bouchard et al, 1986; Fox, 1984). Regardless of genetic differences between individuals who self select active and sedentary lifestyles, it has also been demonstrated that previously sedentary individuals who increase their activity levels can substantially increase their maximal aerobic power (deVries, 1975). We reported a $27 \%$ increase in $\mathrm{VO}_{2}$ max for previously sedentary elderly individuals who completed a 4-month exercise programme (Dustman et al, 1984; Steinhaus et al, in press). Such findings suggest that although maximal aerobic power and exercise stamina may be genetically influenced, their ultimate values are highly dependent on level of physical activity.

It should be noted that no injuries or incidents occurred during any of the 79 maximal exercise tests we conducted, and approximately half of these tests were performed by previously sedentary individuals with poor to fair fitness levels. These results demonstrate that with careful preexercise health screening, orientation, and physician supervision, older low fit individuals can safely exercise to maximal oxygen uptake on a treadmill. In addition to screening for exercise intolerance, this procedure may be of use for demonstrating the feasibility of exercise to inactive individuals and for prescribing target exercise heart rates for those who are beginning an exercise programme.

In summary, we have described important differences between aerobically high and low fit individuals on measures of cardio-respiratory endurance, resting heart rate, resting blood pressure, and recovery heart rates. Clearly, the physiological profiles of the older active individuals resembled more closely the profiles of young high fit individuals than those of age-matched sedentary men. The nature of cardiovascular response differences 
between active and sedentary people may contribute to reduced CHD risk.

\section{ACKNOWLEDGEMENT}

This research was supported by the Veterans Administration.

\section{References}

American College of Sports Medicine, 1986. Guidelines for Exercise Testing and Prescription. 3rd Edition. Philadelphia, Lea and Febiger, 9-30.

Balke, B. and Ware, R. W., 1959 "An Experimental study of physical fitness of Air Force personnel". US Armed Forces Med.J. 10: 675-688.

Blackburn, H., 1983 "Physical activity and coronary heart disease: A brief update and population view". J.Cardiac Rehab. 3: 101-111.

Bouchard, C., Lesage, R., Lortie, G., Simoneau, J.-A., Hamel, P., Boulay, M. R., Perusse, L., Theriault, G. and Leblanc, C., 1986 "Aerobic performance in brothers, dizygotic and monozygotic twins". Med.Sci.Sports Exerc. 18: 639-646.

Cooper, K. H., 1977. The Aerobics Way. New York, Evans and Company, 280-281.

Dehn, M. M. and Bruce, R. A., 1972 "Longitudinal variations in maximal oxygen intake with age and activity". J.Appl.Physiol. 33: 805-807.

deVries, H. A., 1975. Physiology of Exercise and Aging. In: D. S. Woodruff and J. E. Birren (eds.), Aging. New York, Van Nostrand, 257-276.
deVries, H. A., Wiswell, R. A., Bulbulian, R. and Moritani, T., 1981 "Tranquilizer effect of exercise". Am.J.Physical.Med. 60: 57-66.

Dustman, R. E., Ruhling, R. O., Russell, E. M., Shearer, D. E., Bonekat, H. W. Shigeoka, J. W., Wood, J. S. and Bradford, D. C., 1984 "Aerobic exercise training and improved neuropsychological function of older individuals". Neurobiol.Aging 5: 35-42.

Fox, E. L., 1984. Sports Physiology. New York, Saunders.

Fox, E. L. and Matthews, D. K., 1981. The Physiological Basis of Physical Education and Athletics. New York, Saunders, 3rd Edition, 534-535.

Heath, G. W., Hagberg, J. M., Ehsani, A. A. and Holloszy, J. O., 1981 “A physiological comparison of young and old endurance athletes". J.Appl. Physiol. 51: 634-640.

Larson, E. B. and Bruce, R. A., 1987 "Health benefits of exercise in an aging society". Arch.Inter.Med. 147: 353-356.

Paffenbarger, R. S., Hyde, R. T., Wing, A. L. and Hsieh, C.-C., 1986 “Physical activity, all-cause mortality, and longevity of college alumni". N.Engl.J. Med. 314: 605-613.

President's Council on Physical Fitness and Sports, 1977. Physical Fitness Research Digest. Series 7, No. 2, Washington D.C., 2.

Steinhaus,, L. A., Dustman, R. E., Ruhling, R. O., Emmerson, R. Y., Johnson, S. C., Shearer, D. E., Latin, R. W., Shigeoka, J. W. and Bonekat, H. W. "Aerobic capacity of older adults: a training study". J.Sports Med.Phys. Fitness (in press).

Taylor, H. L., Buskirk, E. and Henschel, A., 1955 "Maximal oxygen intake as an objective measure of cardiorespiratory performance". J.Appl.Physiol. 8: 73-78.

Title:

Author:

\title{
WOMEN IN SPORT. A SELECT BIBLIOGRAPHY
}

Publishers:

\author{
Michele Shoebridge
}

Mansell Publishing Ltd., London, 1987

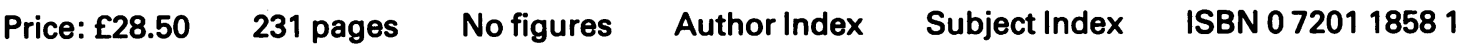

The growing interest in Women in Sport over the past decade or so, has resulted in an expanding body of research that covers a wide range of disciplines. This select bibliography, compiled by Michele Shoebridge of The Sports Documentation Centre at the University of Birmingham, is a most welcome additional reference work contributing to this burgeoning field of study.

Miss Shoebridge has compiled the most complete and up-to-date bibliography of the subject and, as such, it is a "must" for all students of this multi-disciplinary field of work. The time period spanned begins at 1890 with the Modern Olympics; the categories of material include Monographs and Conference Proceedings, Bibliographies, parts of more general books and conference papers, theses and articles, the latter necessarily limited to research published from 1970 onwards due to the wealth of material available. Apart from the articles, many of the references are annotated. The main body of the book is subdivided under headings that cover the major subject areas and these in turn contain sub-sections on relevant topics. For instance, the section entitled "Physiological Aspects" contains a total of 235 references sub-divided under headings such as menstruation, nutrition and physical fitness. The section entitled "Sociological Aspects" (186 references) covers material that includes administration, sponsorship, socialisation and attitudes towards women in sport. A chapter entitled "Individual Sports", with 476 references relating to 38 different sports including Rugby Football, Martial Arts and Dance, demonstrates the wide range of sporting activities in which women are participating.

As with any reference work that is multi-disciplinary in nature, there are problems with organisation and classification. For instance, notwithstanding a whole sub-section entitled "Pregnancy", a further two articles are found on pregnancy, in another section entitled "Physical Fitness". Therefore, readers should beware of referring only to the sections that are prima facie relevant to their own research.

In the Preface (page ix) Miss Shoebridge notes that space has prevented her from including references to research currently being undertaken on inequality between the sexes in schools. This is, in my opinion, the most unfortunate and regrettable omission. As I believe most strongly, and have stated as much throughout my own writings on this subject (to which nine references appear), that much of what characterises the deficiencies in the roles played by women in sport can be traced back to the way young girls, especially those in primary education, are treated at school in physical education classes and games. It follows that any serious attempt to come to grips with women's sporting participation and achievements must take into account the beliefs and attitudes with which women are imbibed in their formative early years. Sad, then, that students of this subject will have to look elsewhere for the relevant bibliography.

Having said that, this book will prove to be invaluable to anybody who wants to understand fully this most important cultural phenomenon. Ms Shoebridge has made an important contribution to the subject and it is hoped that she will continue to do so by updating regularly her select bibliography. 